\title{
Commentary: Ablation of atrial fibrillation: Clarity over heterogeneity
}

J. Scott Rankin, MD, Harold G. Roberts, MD, and Vinay Badhwar, MD

Video clip is available online.

In the current issue of the Journal, Huang and co-authors ${ }^{1}$ present a meta-analysis of 7 clinical trials in an attempt to further address the merit of catheter ablation (CA) or surgical ablation (SA) for the treatment of atrial fibrillation (AF). The trials selected by the authors were published between 2012 and 2018 and totaled 583 patients. The majority involved stand-alone subjects, yet one of the 7 trials involved patients with concomitant rheumatic valvular heart disease. Left-sided lesions and only radiofrequency energy use were assessed. The evaluation of procedural and 1-year efficacy outcomes registered femoral vascular and pneumothorax complications as significant for $\mathrm{CA}$ and SA, respectively. Although neither CA nor SA methods met current standards, 3 useful observations were provided: (1) complications of CA and SA were minor and equivalent, (2) SA was approximately 3 times more effective in rhythm conversion, and (3) the relative benefits of SA over CA were similar for paroxysmal and persistent AF.

From the Department of Cardiovascular and Thoracic Surgery, West Virginia University, Morgantown, WVa.

Disclosures: The authors reported no conflicts of interest.

The Journal policy requires editors and reviewers to disclose conflicts of interest and to decline handling or reviewing manuscripts for which they may have a conflict of interest. The editors and reviewers of this article have no conflicts of interest.

Received for publication May 10, 2020; revisions received May 10, 2020; accepted for publication May 12, 2020; available ahead of print May 30, 2020.

Address for reprints: Vinay Badhwar, MD, Department of Cardiovascular and Thoracic Surgery, West Virginia University, 1 Medical Center Drive, Morgantown, WV (E-mail: vinay.badhwar@wvumedicine.org).

J Thorac Cardiovasc Surg 2022;163:994-6

$0022-5223 / \$ 36.00$

Copyright (c) 2020 by The American Association for Thoracic Surgery

https://doi.org/10.1016/j.jtcvs.2020.05.051

Huang and co-authors ${ }^{1}$ are to be congratulated on their diligently prepared meta-analysis that further supports the recent literature on the merits of SA. However, the reader must realize this data assembly represents a heterogeneous group of patients with both paroxysmal and persistent $\mathrm{AF}$, as well as those with both lone $\mathrm{AF}$ and valvular-associated AF. Although the overarching message that $\mathrm{CA}$ and SA were equivalently low risk yet SA conveyed superior 1-year rhythm effectiveness is valuable, the AF type and lesion set heterogeneity make it difficult to interpret the actual reported effectiveness outcomes.

The benefits of restoring sinus rhythm in patients with $\mathrm{AF}$ are now well accepted..$^{2-8}$ For patients undergoing open valve and coronary bypass procedures, concomitant Cox Maze IV SA (Figure 1) is the current standard because the atria are accessible, biatrial lesions are feasible, sinus conversion rates are more than $80 \%$, and long-term quality of life and survival are significantly enhanced. ${ }^{2-5}$ Huang and co-authors ${ }^{1}$ presented varied consensus positions on the indications and methods for ablation, some of which are now outdated. For definitive clarity, the recent clinical practice guidelines and multidisciplinary expert consensus documents have provided a clear and unified approach to the management of $\mathrm{AF}$ with $\mathrm{CA}$ or SA. ${ }^{6-8}$ These all dutifully compartmentalized recommendations based on the interpretation of the best evidence, 1-year outcomes, type of AF, and operation. The unified position from the 


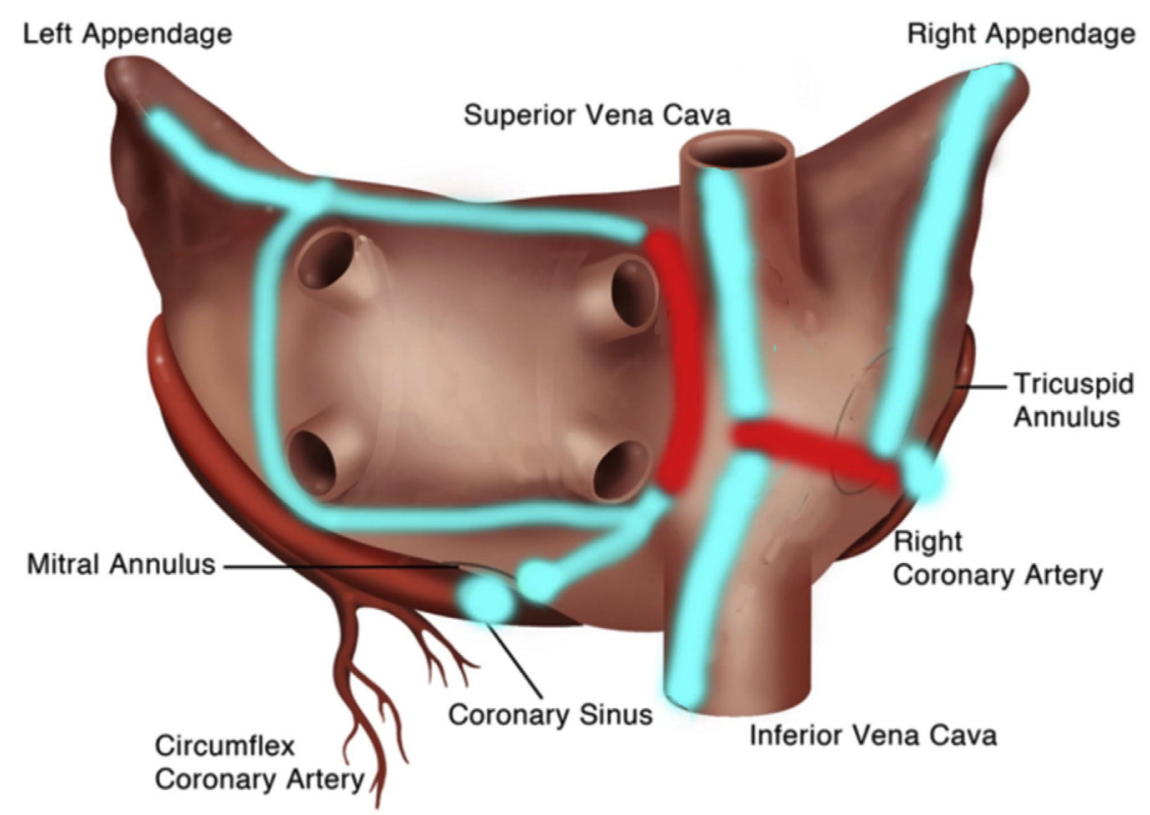

Incision Cryoablation

FIGURE 1. Cox Maze IV biatrial lesion set. ${ }^{2}$

American Association for Thoracic Surgery, The Society of Thoracic Surgeons, and the Heart Rhythm Society can be summarized as follows: (1) SA at the time of mitral operations is recommended (Class 1); (2) SA at the time of aortic valve or coronary bypass operation is recommended (Class 1); (3) SA by pulmonary vein isolation alone is not recommended when the left atrium is greater than $4.5 \mathrm{~cm}$ or if moderate or greater mitral regurgitation is present (Class III); and (4) SA for stand-alone AF after

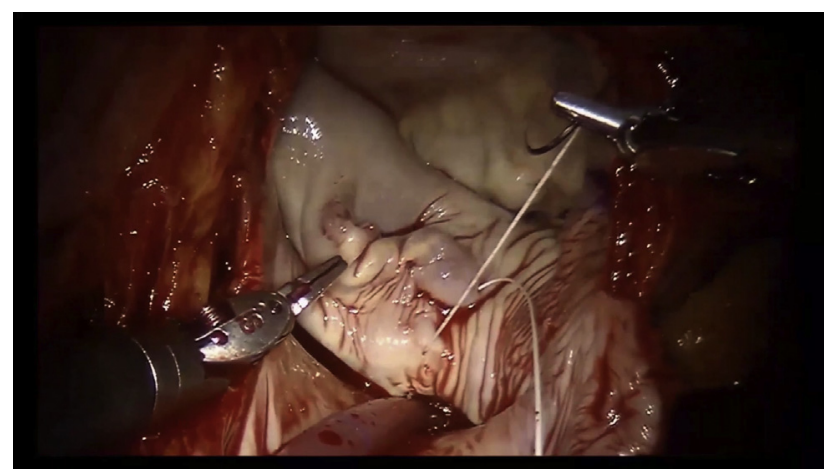

VIDEO 1. Robotic stand-alone Cox Maze IV performed with cryoablation. Left-sided lesions include the epicardial coronary sinus lesion, endocardial mitral line, inferior box lesion that extends into the left atrial appendage, and superior box lesion to complete pulmonary vein encircling. Right-sided lesions include a vertical atriotomy in the caudal third of the right atrium, the tricuspid completion line, the superior and inferior vena caval lines, and the right atrial appendage line, which are all performed so as not to disturb the mid right atrial body. Video available at: https:// www.jtcvs.org/article/S0022-5223(20)31274-5/fulltext. antiarrhythmic medications is reasonable for persistent AF (Class IIA) and paroxysmal AF (Class IIB). ${ }^{6-8}$ For patients without structural heart disease, the CA management of paroxysmal $\mathrm{AF}$ is a reasonable first therapy and for persistent AF with a small left atrium, but once AF recurs or left atrial size is large, SA consideration is warranted for improved effectiveness. ${ }^{8}$

Huang and co-authors ${ }^{1}$ infer that SA should be applied more frequently as the primary ablation approach. While randomized trials of current techniques should be completed, given that SA is now being performed effectively with minimally invasive and robotic approaches (Video 1), it is reasonable to advocate for a greater role for minimally invasive SA in the management of stand-alone AF.

\section{References}

1. Huang H, Wang Q, Xu J, Wu Y, Xu C. Comparison of catheter and surgical ablation for atrial fibrillation: a systemic review and meta-analysis of randomized trials. J Thorac Cardiovasc Surg. 2022;163:980-93.

2. Alreshidan M, Roberts HG, Rankin JS, Wei LM, Badhwar V. Current approach to surgical ablation for atrial fibrillation. Semin Thorac Cardiovasc Surg. 2019;31: $141-5$.

3. Ad N, Holmes SD, Rongione AJ, Badhwar V, Wei L, Fornaresio LM, et al. The long-term safety and efficacy of concomitant Cox maze procedures for atrial fibrillation in patients without mitral valve disease. J Thorac Cardiovasc Surg. 2019; 157:1505-14.

4. Musharbash FN, Schill MR, Sinn LA, Schuessler RB, Maniar HS, Moon MR, et al Performance of the Cox-maze IV procedure is associated with improved long-term survival in patients with atrial fibrillation undergoing cardiac surgery. J Thorac Cardiovasc Surg. 2018;155:159-70.

5. Rankin JS, Lerner DJ, Braid-Forbes MJ, McCrea MM, Badhwar V. Surgical ablation of atrial fibrillation concomitant to coronary-artery bypass grafting provides 
cost-effective mortality reduction. J Thorac Cardiovasc Surg. 2020;160: 675-86.e13.

6. Badhwar V, Rankin JS, Damiano RJ, Gillinov AM, Bakaeen FG, Edgerton JR, et al. The Society of Thoracic Surgeons 2017 clinical practice guidelines for the surgical treatment of atrial fibrillation. Ann Thorac Surg. 2017;103:329-41.
7. Ad N, Damiano RJ Jr, Badhwar V, Calkins H, La Meir M, Nitta T, et al. Expert consensus guidelines: examining surgical ablation for atrial fibrillation. $J$ Thorac Cardiovasc Surg. 2017;153:1330-54.e1.

8. Calkins H, Hindricks G, Cappato R, Kim YH, Saad EB, Aguinaga L, et al. 2017 HRS/EHRA/ECAS/APHRS/SOLAECE expert consensus statement on catheter and surgical ablation of atrial fibrillation. Heart Rhythm. 2017;14:e275-444.
See Article page 980.

\section{Commentary: What would Sir Francis Bacon think of us now?}

\author{
Alden H. Harken, MD
}

At the beginning of the seventeenth century, "science" was awash in superstition, unguided speculation, and theology. Voltaire famously credited Francis Bacon with the concept and development of the "scientific method." Bacon proposed that with a thoughtful perusal of facts, one could induce a unifying hypothesis and deduce the validity of that hypothesis by rigorous challenge with facts. Descartes took the next step by declaring that knowledge is created by the progression from one clear idea to the next. A century later, Hegel posited that knowing and the essence of reality must coincide. So, it was a small step for Kierkegaard, in the following century, to criticize rational knowledge stating that "truth is subjectivity," anticipating William James, who wrote that truth is not the quality of an idea, conversely "truth is made by an act of will."

In the accompanying manuscript, a conscientious group of investigators have assessed the beneficial and adverse effects of catheter ablation and surgical ablation of atrial fibrillation. ${ }^{1}$ Atrial fibrillation is a common clinical problem. Both surgical ablation and catheter ablation are frequently administered therapies. Therefore, the authors are asking a practical and important question. Fortunately, there is a wealth of information published on this topic. By scouring the medical literature, the authors identified

From the UCSF-East Bay (retired), Alamo, Calif.

Disclosures: The author reported no conflicts of interest.

The Journal policy requires editors and reviewers to disclose conflicts of interest and to decline handling or reviewing manuscripts for which they may have a conflict of interest. The editors and reviewers of this article have no conflicts of interest.

Received for publication May 21, 2020; accepted for publication May 21, 2020; available ahead of print June 5, 2020.

Address for reprints: Alden H. Harken, MD, Department of Surgery, University of California, San Francisco, East Bay, 1565 Alamo Way, Alamo, CA 94602 (E-mail: alden.harken68@gmail.com).

J Thorac Cardiovasc Surg 2022;163:996-7 $0022-5223 / \$ 36.00$

Copyright $₫ 2020$ Published by Elsevier Inc. on behalf of The American Association for Thoracic Surgery

https://doi.org/10.1016/j.jtcvs.2020.05.072
Check for updates

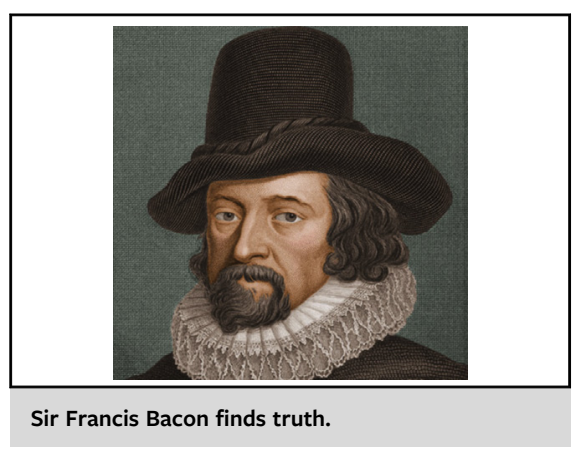

CENTRAL MESSAGE

Metaphysics is "kind of" physics;

however, you can't prove it. A

meta-analysis provides the au-

thor's opinion, but again, they

can't prove it.

2810 studies addressing this issue. By scanning these manuscripts, they were able to cull 2748, leaving 62 eligible studies. Critical examination of these manuscripts further depleted the investigations examined down to 7 analyses of 583 patients. Clinical investigation is hard to do, and it is even harder to do well. The 2810 manuscripts are available to everyone. Selecting 7 studies of 2810 requires a huge amount of work.

Cognitive assumptions can distort our observations and even influence our conclusions. We think of bias in a pejorative way; however, it is hard to imagine a decision that anyone ever makes that is not biased. When we must acknowledge this pre-judgmental influence, we call it experience. The Cochrane Collaboration has plowed a lot of scholarly energy into the domains of bias, and they categorize the varieties as selection, performance, detection, attrition, and reporting biases. Imagine, for instance, that you randomly (the word itself sounds pretty good) empanel your jury from a group of people phoning in for a tee time at Mar-A-Lago versus a group (again randomly) 